\title{
An Investigation into the Interactions Between Positive and Negative Aspects of Personality, Perfectionism, Coping, and Locus of Control: A Latent Profile Analysis
}

\author{
Murat Boysan $^{1 *}$, Erkan Kiral \\ ${ }^{1}$ Department of Psychology, Faculty of Social Sciences, Yuzuncu Yil University, Van, Turkey \\ ${ }^{2}$ Department of Educational Administration, Supervision, Planning and Economy, Adnan Menderes University, Aydın, Turkey
}

\begin{abstract}
Our main aim was to investigate whether a taxonomic or a continuum model best fit to the associations between positive and negative aspects of trait psychological constructs. Using a factor analytic approach, we found that positive aspects of personality, perfectionism, coping, and locus of control were discernible from negative aspects of these constructs. Adhering to latent profile analysis procedure, we found four latent homogenous subsets among which individuals differentiated in their levels of positive traits. These four latent homogenous groups were labeled as 'Extremely low positive traits with high agreeableness', 'Low positive traits', 'High positive traits with high agreeableness', and 'High positive traits'. Latent class analyses demonstrated that participants who reported greater scores on positive traits were classified into two groups based on agreeableness scores (latent class 3 vs latent class 4). However, these two high positive traits groups did not significantly differentiate in other positive or negative traits. At the other extreme, those who scored extremely low on positive traits were also distinguishable from 'Low positive traits' group (latent class 2) dependent on high agreeableness scores (latent class 1) and at higher risk in terms of lowest positive traits among these four latent homogenous groups. It was appeared that agreeableness operates counterproductively among low positive individuals. It is concluded that multidimensional trait constructs seem to have two aspects including positive and negative facets rather than operating along a continuum or being simple opposites.
\end{abstract}

Keywords: psychological strengths, positive and negative well-being, positive traits, Taxonomic model, continuum model

\section{INTRODUCTION}

Many scholars have increasingly argued that research has disproportionately focused on pathological or negative

*Correspondence: boysan.muratagmail.com

Department of Psychology, Faculty of Social Sciences,

Yuzuncu Yil University, 65080 Van, Turkey

Tel: 0 (432) 2251051 / 22511, Fax: 0 (432) 2251188

\section{Sleep and Hypnosis}

Submit your manuscript at www.sleepandhypnosis.org aspects of psychological constructs, whilst strengths and preventive factors that make life worth living may have more practical merit for various lines of interventions (Seligman \& Csikszentmihalyi, 2000). On the other hand, difficulties in elaboration of firm definitions of this aspect of human nature, there have been ongoing attempts to understanding and generating discourse on various ways of defining human strengths. Psychological constructs such as functionality or adaptiveness have long been used as indicators of 'normality' to an extent to which was representative of well-being. Even though, there are a 
vast array of difficulties to be discussed and settled in definitions of these conceptualizations, particularly to assess well-being (Baltes \& Staudinger, 2000; Sternberg, 1998).

On the other hand, it seems that human strengths may primarily lie in the ability to flexibility apply sources toward a goal (Staudinger, Marsiske, \& Baltes, 1995; Staudinger \& Pasupathi, 2000). Peterson and Seligman (2004) provided a comprehensive definition of character strengths and virtues. The Values in Action (VIA) classification specifies 24 character strengths important for psychological fulfillment and happiness. Accumulated evidence supports that 24 positive human strengths are cross culturally ubiquitous and shows significant associations with life satisfaction and other positive facets (Biswas-Diener, 2006; Shimai, Otake, Park, Peterson, \& Seligman, 2006; Toner, Haslam, Robinson, \& Williams, 2012), even among children as young as three (Park \& Peterson, 2006).

To our opinion, psychological strengths are internal sources that encompass positive facets of specifically multidimensional psychological traits such as personality, perfectionism, locus of control. Also we suggest that the term psychological strengths by definition is not an alternative conceptualization of human or character strengths. Rather they may be first-order dimensions of psychological characteristics playing pivotal role in the development and maintenance of secondary meta-traits conceptualized as character strengths that embrace or are supported by psychological strengths referring to positive aspects of psychological traits.

Positive and negative aspects of experiences as well as of psychological characteristics seem to be closely interrelated (Aspinwall \& Staudinger, 2003). The people deliberately stick to the positives to derive growthfacilitating meaning, and to generate and sustain a harmony with negatives in life are probably more close to a life worth living; whereas the relative balance between positives and negatives can be amenable to the features of the life domain. Positives and negatives may function independently, but in some stances, growth may be promoted by adversities or is directly dependent to losses (Calhoun \& Tedeschi, 2012). Despite the fundamental dependencies between positive and negative, the premise that positive and negative states are symmetrical in nature would lead misleading conclusions without taking the context into consideration (Isen, 2003). Furthermore the connections between positive and negative characteristics may be more complicated in comparison to conceptualizations heavily relying on a simple opposite relation (Davidson \& Sutton, 1995; Isen, $2002 b)$. There are situations and contexts that characteristics or processes work in one setting may be liabilities in another, and vice versa.

To date, research examining tentative sequelaes of vulnerability factors has largely focused on negative psychological outcomes. Accordingly, if we assume that these bidirectional relations and influences guided by clinical and non-clinical experience, then we would expect in each case vulnerabilities will primarily be tied to illbeing, whilst psychological strengths will be mainly tied to well-being. To the best of our knowledge, examining the possible outcomes of respective multidimensional psychological conceptualization, findings would be more likely to be in a way as emphasized earlier. However, research has long documented links between positive traits such as extraversion and a behavioral approach system in the left frontal cortex, a system largely implicated in initiating approach behavior, pursuit of rewards and regulating positive affect (Davidson, 1992; Sutton \& Davidson, 1997; Zuckerman, 1995). By contrast, psychological liabilities such as neuroticism seem to be associated with the behavioral inhibition system in the right brain, conceptualized as central to avoidance behavior and negative affectivity (LeDoux, 1996). Therefore, relatively irrespective of psychological vulnerabilities a constellation of psychological strengths may function together in promoting individual's wellbeing, as can be the case for psychological vulnerabilities, vice versa. Using the Values in Action Inventory of Strengths, two studies in clinical and non-clinical samples conducted by Huta and Hawley (2010) found significant linkages of character strengths to positive well-being in terms of life satisfaction, positive affect, vitality, meaning and elevating experiences. Character strengths were predictive of positive treatment outcomes in clinical 
sample. Strengths and vulnerabilities were correlated at most moderately indicative of that these dimensions are not simple opposites.

Given these considerations in the further analysis, all psychological characteristics seem to have positive and negative facets, tentatively functioning together. Perfectionism is one of these multidimensional constructs that Hamachek (1978) was the first suggested two forms of perfectionism to be distinguished, a positive perfectionism labeled 'normal perfectionism' and a negative form labeled 'neurotic perfectionism'. Although perfectionism has been generally conceived as a general risk factor for psychopathology (Obsessive Compulsive Cognitions Working Group, 2005; Shafran \& Mansell, 2001), a large body of evidence has accumulated confirming that two forms of perfectionism can be distinguished. The distinction between these two basic forms has been presented with many labels: positive striving vs maladaptive evaluation concern (Frost, Heimberg, Holt, Mattia, \& Neubauer, 1993), active vs passive (Adkins \& Parker, 1996), positive vs negative (Terry-Short, Owens, Slade, \& Dewey, 1995), adaptive vs maldaptive (Rice, Ashby, \& Slaney, 1998), functional vs dysfunctional (Rheaume et al., 2000), healthy vs unhealthy (Stumpf \& Parker, 2000), perfectionistic strivings vs perfectionistic concerns (Stoeber \& Otto, 2006), and self-oriented vs socially prescribed (Hewitt \& Flett, 2004; Stoeber, 2014). Using a factor analytic approach, Frost et al. (1993) classified all dimensions measured with Frost's and Hewitt's multidimensional psychometric tools of perfectionism in two factors. One factor subsumed personal standards, organization, selforiented perfectionism and other-oriented perfectionism; and other factor subsumed concern over mistakes, doubts about actions, socially prescribed perfectionism, parental expectations and parental criticism. In the original validation study, Frost et al. accentuated that organization sub-scale refers to positive perfectionism and should not be conceived as pathological. When the subscale scores summed for these two factors, positive strivings was strongly associated with positive affect and unrelated to depression and negative affect. The case was inverse for maladaptive evaluation concerns factor. In a systematic review of the literature, Stoeber and Otto (2006) suggested that two dimensional approach to perfectionism best fit to previous findings. Authors demonstrated strong evidence confirming that positive perfectionistic strivings are associated with positive psychological outcomes and healthy perfectionistics exhibit higher levels of positive characteristics.

Personality is an integral part of happiness and should be more comprehensively understood to be accounted for tentative mechanisms of happiness (Sheldon, 2004). Personality traits explain a greater proportion of the variance up to $50 \%$ in individual differences in well-being (Diener, Suh, Lucas, \& Smith, 1999). Personality traits are biological in nature and include long-standing inclinations encompassing attitudes and behaviors consistent over time and across situations (McCrae \& Costa, 1996). Of prime interest has been two personality traits of extraversion and neuroticism by researchers consistently found that that extraverts report being happier relative to introverts and neurotics report being less happier in comparison to individuals with good emotional regulation (Costa \& McCrae, 1980; Costa, McCrae, \& Zonderman, 1987; McCrae \& Costa, 1991; Steel \& Ones, 2002). Although relatively less focused on in comparison to extraversion and neuroticism, agreeableness and consciousness have also been tied to happiness (McCrae \& Costa, 1991).

According to McCrae and Costa (1991), there are several ways personality traits exert influence on happiness. While neuroticism debilitating extraversion promotes the positive affect, in turn, both traits effect happiness through affect is exemplary to temperamental causal path. Individuals with respective personality traits may establish conditions cultivating happiness or unhappiness. Extraverts may consistently seek out social interactions, which, in turn, influence happiness through elevating positive affect is illustrative to instrumental casual sequence. Happiness increasing strategies associated with personality characteristics seem to promote happiness through volitional behaviors which mediates the relation between personal inclinations and well-being (Eryilmaz, 2012; Tkach \& Lyubomirsky, 2006). 
Locus of control is one of the most widely studied personality traits in the literature and is conceived as one of the four facets of core-self evaluation process along with neuroticism, self-efficacy, and self-esteem (Judge, Locke, \& Durham, 1997). In an extensive meta-analysis of these constructs, Judge, Erez, Bono, and Thoresen (2002) vividly demonstrated that these four concepts measure the same general conceptual framework. There has been a considerable emphasis on the pivotal role of selfdetermination, a sense of control, independence and internal locus of evaluation with regard to a constellation of closely related conceptualizations of well-being such as fully functioning, self determination and flow experience (Csikszentmihalyi, 2008; Ryan \& Deci, 2000; Ryff, 1989). Our contention for the linkages between locus of control and happiness would be in consonant with the previously conceptualized pathways within the big five personality framework and well-being proposed by McCrae and Costa (1991) that specifically individuals with greater tendency of internal control have been consistently proven to deal more successfully with life challenges and have better mood which, in turn, significantly contribute to personal happiness (Parkes, 1984; Petrosky \& Birkimer, 1991; Ward \& Kennedy, 1992).

Berscheid (2003) asserted that examining positive aspects of negative states and negative aspects of positive states should be a substantial part of psychology of strengths. Based on these considerations, we have the following hypothesis for the data presented here: i) psychological strengths in terms of positive aspects of multidimensional variables addressed in the study and vulnerabilities in terms of negative facets of these psychological constructs will be subsumed in two main dimensions through principal components analysis ii) the sample of community people will be categorized in more than one homogenous latent subgroups due to psychological strengths of personality, locus of control and perfectionism scores in a latent profile analysis; iii) merely some of vulnerability scores will significantly differentiate across latent homogenous subsets, but most of psychological vulnerabilities will not differ which is indicative of relatively independent relations between psychological strengths and vulnerabilities.

\section{METHOD}

\section{Participants and Procedure}

Three hundred and thirty-two participants participated in the study, aged between 21-42. The mean age of the participants was $24.24(\mathrm{SD} \pm 3.05)$ and greater proportion were females ( $\mathrm{N}=231 ; 69.58 \%)$. Written informed consent was taken from each participant after a brief description of the investigation. Volunteers completed the measures in their classroom.

\section{Psychometric Instruments}

Coping Inventory for Stressful Situations-Short Form (CISS-SF). The CISS-SF is a 21-item shortened version developed by Endler and Parker (1990) to assess generic coping styles in the face of stressful situations. The CISSSF yields scores on three sub-scales: task-oriented coping, emotion-oriented coping, and avoidance-oriented coping. Each sub-scale is comprised of seven items rated on a five-point Likert scale ranging from 1 (Not at all) to 5 (Very much). The Turkish version is demonstrated to have good validity and reliability. Internal consistency coefficients were .72, .77, and .74, respectively (Boysan, 2012).

Levenson Multidimensional Locus of Control Scale-Short Form (LMLS-SF). The measure is a self report questionnaire developed by Levenson (1973) to assess different aspects of locus of control. A shortened version of the scale validated by Kıral (2012) in a sample of Turkish public primary school administrators. The short version consists of 19 items tapping into three subscales: Internal locus of control, powerful others and change. External locus of control measured in two dimensions capturing individuals' beliefs that their lives are controlled by powerful others and chance. Items of the short version are rated on a sixpoint measure from 1 (strongly disagree) to 6 (strongly agree). The subscales were demonstrated to have good validity and adequate internal reliability $(a=.77, .60$. and .62 ; respectively).

Big Five Inventory (BFI). The initial validation study of the BFI was conducted by John and Srivastava (1999) to 
assess five dimensions of personality: extraversion, agreeableness, conscientiousness, neuroticism and openness to experiences. The BFI is comprised of 44 items rated on a five-point measure, ranging from strongly disagree to strongly agree. The Turkish version had high internal consistency. Cronbach's alphas were from .79 to .88 (Evinç, 2004).

Frost Multidimensional Perfectionism Scale (FMPS). The FMPS is a self-administered scale including 35 items to assess a multifaceted psychological construct of perfectionism (Frost, Marten, Lahart, \& Rosenblate, 1990). Each item has a five-point response scale ranging from "strongly disagree" to "strongly agree". The measure yields scores on six subscales: Personal standards, concern over mistakes, doubts about actions, parental expectations, parental criticism, and organization. The Turkish version was adapted by Kağan (2011) in a college sample. The Cronbach's alphas for the subscales ranged from .64 to .94 .

Penn State Worry Questionnaire (PSWQ). The PSWQ is a widely used self-report scale of pathological worry developed by Meyer, Miller, Metzger, and Barkovec (1990). The scale has 16 items rated on a five-point measure . Five items are reversely coded (item 1, 3, 8, 10, and 11). The Turkish version of the PSQW had sound psychometric properties. Internal reliability was .88 (Boysan, Keskin, \& Beşiroğlu, 2008).

\section{Statistical Analysis}

Initially, we computed descriptive statistics. We performed principal components analysis to cluster dimensions of personality, locus of control, generic coping styles, and perfectionism into two factors as psychological weaknesses and strengths. Then, we adhered to a mixture modeling approach to investigate optimal number of latent homogenous subsets using positive aspects of psychological variables. We used Akaike's Information Criterion (Akaike, 1987), Bayesian Information Criterion (Schwartz, 1978), and Adjusted Bayesian Information Criterion (Sclove, 1987) to guide decision on the number of classes in latent profile analysis.
The lower the value derived from these model fit indexes, the better the model fit to the data set. Additionally, we performed the bootstrapped likelihood ratio test (BLRT) to detect optimal number of latent classes obtained in the latent profile analysis. BLRT is a likelihood based method to compare nested latent class models. This method generates and uses bootstrap samples to estimate the log likelihood difference test statistic. The BLRT provides a $p$ value of statistical significance to be used to compare the increase in model fit between $k$ and $k-1$ class models (McLachlan \& Peel, 2000). A P-value less than significance threshold is indicative of $k-1$ class solution best fit to the model in comparison to $k$ class solution. A simulation study explored the performance of these model fit indexes, it was found that the BLRT outperformed the others and the second best was BIC to decide the optimal number of classes in mixture modeling (Nylund, Asparoutiov, \& Muthen, 2007). We utilized all of these tools as model fit indexes in the current. Yet, the Entropy criterion was also computed. Entropy is an index indicating the accuracy of classification of the respondents in the respective classes, with higher values closer to 1.0 is suggestive for the solution better fit to the data set.

\section{RESULTS}

\section{Explanatory Factor Analysis}

An EFA was run to explore the two dimensional structure of the positive and negative psychological characteristics. The Kaiser-Meyer-Olkin measure of sampling adequacy indicated a good value of 0.75 . Bartlett's test of sphericity indicated a chi square value of $1562.894 \mathrm{df}=120 \mathrm{p}<.001$.

A varimax rotated principal components analysis was performed. The two-factor solution explained $38.76 \%$ of the variance. First factor accounted $20.01 \%$ and second factor accounted $13.75 \%$ of the total variance. Five subscales of the FMPS in terms of concern over mistakes, doubts about actions, parental criticism, parental expectations, and personal standards which represent negative dimensions of perfectionism classified in factor 1. Neuroticism dimension of big five personality construct, emotional-oriented coping style, powerful others 
dimension of the locus of control scale and total scores of the pathological worry were all subsumed under the first factor. We considered this factor as personal weaknesses factor. Rotated factor loadings in this factor were higher than 0.34 .

Conscientiousness, openness, extraversion and agreeableness dimensions of the big five personality pattern classified in second factor. Organization sub-scale of the Multidimensional Perfectionism Scale, task-oriented coping dimension of the CISS, and internal control dimension of the Locus of Control Scale were allocated into second factor as well. Rotated factor loadings in second factor were higher than 0.37 .

Chance sub-scale of the Locus of Control Scale and avoidance-oriented coping style were found to be complex variables which could not be classified in either group due to factor loadings very close to each other. These two variables also had rotated factor loadings very lower than 0.30 (Tabachnich \& Fidell, 2012).

\section{Latent Profile Analysis}

LPA was run to obtain homogenous latent subgroups due to positive psychological traits derived from EFA within the sample, and relate these latent classes to negative facets of the measures. An advanced statistical method of LPA, an extension of latent class analysis allows researchers to identify homogeneous subgroups of people due to continuous indicator variables relative to a taxonomy of variables as is the case with exploratory or confirmatory factor analysis. In LPA, individuals are assigned in exclusive classes based on their responses to respective observed variables. A latent class structure of observed psychological constructs (i.e. personality, coping) will indicate profiles of individuals who reveal similar patterns of responses on the observed variables.

LPA was used to detect the optimal number of homogenous latent profiles based on the scores of positive facets of observed psychological variables in terms of organization subscale of the FMPS, task-oriented coping style, four dimensions of big five personality factor structure, and internal locus of control. At the outset, we investigated the model fit beginning from 2 -class to 5 -class solutions. Classes were added consecutively to determine the model best fit to the data according to goodness of fit indexes. The purpose was to derive the optimal number of classes that describe different types of participants based on the response pattern related to measured positive observed variables.

As can be seen in Table 1, LPA revealed that 4-class solution was better than 2-, 3-, and 5-class solutions due to lower AIC, BIC and ABIC values, evidenced by the significance of the BLRT value and an Entropy value close to 1.0. Class 1 was composed of 43 respondents (12.95\%), class 2 was composed of 101 respondents (30.42\%), class 3 was composed of 37 respondents (11.15\%), and class 4 was composed of 151 respondents (45.48\%).

\section{Table 1: Varimax-rotated principal components analyses factor loadings}

\begin{tabular}{lcc} 
& Negative Traits & Positive Traits \\
\hline Concern over Mistakes & $\mathbf{0 . 8 1 3}$ & -0.017 \\
Penn State Worry Questionnaire & $\mathbf{0 . 6 9 6}$ & -0.141 \\
Emotion Oriented Coping & $\mathbf{0 . 6 6 6}$ & -0.162 \\
Doubts about Actions & $\mathbf{0 . 6 6 1}$ & -0.191 \\
Parental Criticism & $\mathbf{0 . 6 5 7}$ & -0.166 \\
Parental Expectations & $\mathbf{0 . 6 0 3}$ & 0.150 \\
Neuroticism & $\mathbf{0 . 5 4 3}$ & -0.276 \\
Personal Standards & $\mathbf{0 . 5 2 6}$ & 0.500 \\
Powerful Others & $\mathbf{0 . 3 2 7}$ & -0.213 \\
Conscientious & -0.156 & $\mathbf{0 . 7 6 8}$ \\
Organization & 0.058 & $\mathbf{0 . 5 9 6}$ \\
Openness & -0.111 & $\mathbf{0 . 5 8 4}$ \\
Task Oriented Coping & -0.038 & $\mathbf{0 . 4 8 9}$ \\
Extraversion & -0.298 & $\mathbf{0 . 4 5 9}$ \\
Agreeableness & -0.088 & $\mathbf{0 . 4 1 6}$ \\
Internal Locus of Control & -0.131 & $\mathbf{0 . 3 6 5}$ \\
\hline
\end{tabular}

Note. Significant factor loadings are boldfaced. 
We run analysis of variance to substantially interpret each class. We compared mean scale scores of the positive aspects of psychological constructs previously used as observed indicators in LPA. We found significant $F$ values for all positive variables indicating substantial differences across latent classes. All positive sub-scale scores means for Class 1 were lower than means for other classes with an exception of agreeableness personality trait. Thus, this profile of Class 1 was referred to individuals with extremely low positive traits with high agreeableness. Mean subs-scale scores for Class 2 were higher than Class 1, albeit respondents in Class 1 scored greater scores merely on agreeableness trait in comparison to Class 2. Although these two classes differentiated in terms of psychological strengths, both latent homogenous groups were comprised of persons with low positive traits relative to both Class 3 and Class 4. Interpretation of the mean scale scores indicated that Class 4 referred to individuals with extremely high positive traits with an exception for agreeableness. Class 3 was comprised of individuals with high agreeableness personality trait; contrarily, mean scale scores of all other positive traits scores other than agreeableness did not substantially differ than individuals assigned in Class 4. Finally, eta squared value was the greatest for agreeableness trait which can be interpreted as that this trait is critical in accounting for the differentiation across four latent homogenous sub-groups. Findings are presents in Table 2.

Significance of differentiation on mean negative subscale scores across latent homogenous groups were assessed using one-way analysis of variance. We found significant differences for chance sub-scale of the Locus of Control Scale, parental criticism dimension of the perfectionism construct and emotion-oriented coping scores across latent classes. Group differences were examined using post hoc analysis. Individuals with low positive traits along with low agreeableness scored lower on chance dimension of locus of control than individuals in both Class 3 and Class 4. Mean Chance dimension score of individuals with extremely low positive traits with high agreeableness did not differ from other three latent classes. Individuals with low positive traits in both Class 1 and Class 2 reported significantly greater scores on emotion-oriented coping in comparison to individuals with extremely high positive traits classified in Class 4.

Table 2: Model fit indices for latent profile analysis

\begin{tabular}{|c|c|c|c|c|c|c|}
\hline $\begin{array}{l}\text { Number of } \\
\text { Latent Classes }\end{array}$ & AIC & $\mathrm{BIC}$ & $A B I C$ & Entropy & BLRT & $\begin{array}{c}\text { Approximate } \\
\text { p value }\end{array}$ \\
\hline 2 & 8814.246 & 8897.959 & 8828.174 & 0.873 & 205.489 & 0.0000 \\
\hline 3 & 8596.755 & 8710.909 & 8615.747 & 1.000 & 233.492 & 0.0000 \\
\hline 4 & 8513.201 & 8657.796 & 8537.258 & 0.921 & 72.128 & 0.0000 \\
\hline 5 & 8584.331 & 8759.367 & 8613.453 & 0.911 & 14.856 & 0.2565 \\
\hline
\end{tabular}

Note. $\mathrm{AIC}=$ Akaike's Information Criterion; BIC= Bayesian Information Criterion; ABIC= Adjusted Bayesian Information Criterion; BLRT = Bootstrapped Likelihood Ratio Test

Table 3: ANOVA comparisons of positive traits across latent homogenous subsets

\begin{tabular}{|c|c|c|c|c|c|c|c|c|c|c|c|c|}
\hline & \multicolumn{8}{|c|}{ Latent Homogenous Subsets } & \multirow[b]{4}{*}{$F(3,328)$} & \multirow[b]{4}{*}{$\mathbf{P}$} & \multirow[b]{4}{*}{$\eta^{2}$} & \multirow[b]{4}{*}{ Post Hoc } \\
\hline & \multirow{2}{*}{\multicolumn{2}{|c|}{$\begin{array}{c}\text { Latent Class } 1 \\
\mathrm{n}=43 \\
\end{array}$}} & \multirow{2}{*}{\multicolumn{2}{|c|}{$\begin{array}{c}\text { Latent Class } 2 \\
\mathrm{n}=101\end{array}$}} & \multirow{2}{*}{\multicolumn{2}{|c|}{$\begin{array}{c}\text { Latent Class } 3 \\
\mathrm{n}=37\end{array}$}} & \multirow{2}{*}{\multicolumn{2}{|c|}{$\begin{array}{c}\text { Latent Class } 4 \\
\mathrm{n}=151\end{array}$}} & & & & \\
\hline & & & & & & & & & & & & \\
\hline & Mean & SD & Mean & SD & Mean & SD & Mean & SD & & & & \\
\hline Agreeableness & 3.94 & 0.27 & 3.10 & 0.33 & 4.69 & 0.13 & 4.01 & 0.27 & 370.515 & .000 & .772 & $\mathrm{LC} 2<\mathrm{LC} 1=\mathrm{LC} 4<\mathrm{LC} 3$ \\
\hline Extraversion & 3.10 & 0.67 & 3.23 & 0.68 & 3.45 & 0.61 & 3.48 & 0.67 & 5.206 & .002 & .045 & $\mathrm{LC} 1=\mathrm{LC} 2<\mathrm{LC} 3=\mathrm{LC} 4$ \\
\hline Conscientious & 2.97 & 0.43 & 3.39 & 0.63 & 4.03 & 0.61 & 4.11 & 0.45 & 72.943 & .000 & .400 & $\mathrm{LC} 1<\mathrm{LC} 2<\mathrm{LC} 3=\mathrm{LC} 4$ \\
\hline Openness & 3.59 & 0.66 & 3.75 & 0.60 & 3.94 & 0.73 & 3.91 & 0.56 & 4.216 & .006 & .037 & $\mathrm{LC} 1<\mathrm{LC} 2<\mathrm{LC} 3=\mathrm{LC} 4$ \\
\hline Organization & 20.30 & 6.33 & 22.83 & 5.94 & 27.19 & 4.04 & 27.18 & 3.31 & 34.070 & .000 & .238 & $\mathrm{LC} 1<\mathrm{LC} 2<\mathrm{LC} 3=\mathrm{LC} 4$ \\
\hline Internal Locus of Control & 30.40 & 5.59 & 33.00 & 5.06 & 32.62 & 6.15 & 34.50 & 5.24 & 7.102 & .000 & .061 & $\mathrm{LC} 1<\mathrm{LC} 2=\mathrm{LC} 3=\mathrm{LC} 4$ \\
\hline Task Oriented Coping & 24.30 & 4.82 & 25.27 & 4.83 & 27.22 & 5.20 & 27.13 & 4.86 & 5.718 & .001 & .050 & $\mathrm{LC} 1=\mathrm{LC} 2<\mathrm{LC} 3=\mathrm{LC} 4$ \\
\hline
\end{tabular}

Note. Latent Class 1 = Extremely low positive traits with high agreeableness, Latent Class $2=$ Low positive traits, Latent Class $3=$ High positive traits with high agreeableness, Latent Class $4=$ High positive traits 


\begin{tabular}{|c|c|c|c|c|c|c|c|c|c|c|c|c|}
\hline & \multicolumn{8}{|c|}{ Latent Homogenous Subsets } & \multirow[b]{4}{*}{$F(3,328)$} & \multirow[b]{4}{*}{$\mathbf{P}$} & \multirow[b]{4}{*}{$\eta^{2}$} & \multirow[b]{4}{*}{ Post Hoc } \\
\hline & \multirow{2}{*}{\multicolumn{2}{|c|}{$\begin{array}{c}\text { Latent Class } 1 \\
n=43\end{array}$}} & \multirow{2}{*}{\multicolumn{2}{|c|}{$\begin{array}{c}\text { Latent Class } 2 \\
\mathrm{n}=101\end{array}$}} & \multirow{2}{*}{\multicolumn{2}{|c|}{$\begin{array}{c}\text { Latent Class } 3 \\
\mathrm{n}=37\end{array}$}} & \multirow{2}{*}{\multicolumn{2}{|c|}{$\begin{array}{c}\text { Latent Class } 4 \\
n=151\end{array}$}} & & & & \\
\hline & & & & & & & & & & & & \\
\hline & Mean & SD & Mean & SD & Mean & SD & Mean & SD & & & & \\
\hline Powerful Others & 19.56 & 3.55 & 18.59 & 4.57 & 17.84 & 5.06 & 18.04 & 4.21 & 1.639 & .180 & .015 & - \\
\hline Chance & 14.85 & 3.75 & 15.93 & 3.80 & 14.41 & 4.09 & 14.53 & 4.10 & 2.868 & .037 & .026 & $\mathrm{LC} 3=\mathrm{LC} 4<\mathrm{LC} 2$ \\
\hline Neuroticism & 3.34 & 0.72 & 3.31 & 0.69 & 3.17 & 0.79 & 3.08 & 0.74 & 2.539 & .057 & .023 & - \\
\hline Personal Standards & 21.07 & 5.44 & 22.69 & 5.22 & 22.97 & 4.68 & 22.38 & 4.77 & 1.290 & .278 & .012 & - \\
\hline Concern over Mistakes & 22.33 & 7.89 & 23.30 & 7.35 & 20.68 & 8.02 & 20.98 & 7.59 & 2.238 & .084 & .020 & - \\
\hline Parental Expectations & 14.80 & 4.95 & 15.17 & 5.33 & 15.43 & 5.09 & 14.58 & 5.09 & 0.426 & .734 & .004 & - \\
\hline Parental Criticism & 9.26 & 4.09 & 9.38 & 3.65 & 8.41 & 3.98 & 7.60 & 3.53 & 5.488 & .001 & .048 & $\mathrm{LC} 3=\mathrm{LC} 4<\mathrm{LC} 1=\mathrm{LC} 2$ \\
\hline Doubts about Actions & 11.40 & 3.68 & 11.16 & 3.23 & 10.32 & 3.79 & 10.16 & 3.64 & 2.409 & .067 & .022 & - \\
\hline Emotion Oriented Coping & 22.07 & 6.93 & 21.58 & 6.18 & 20.68 & 7.16 & 19.63 & 6.03 & 2.756 & .042 & .025 & $\mathrm{LC} 4<\mathrm{LC} 1=\mathrm{LC} 2$ \\
\hline Avoidance Oriented Coping & 21.56 & 6.56 & 22.26 & 5.84 & 20.76 & 8.02 & 21.42 & 5.97 & 0.640 & .590 & .006 & - \\
\hline Penn State Worry Questionnaire & 49.59 & 12.48 & 49.48 & 11.72 & 48.14 & 13.58 & 47.47 & 13.92 & 0.607 & .611 & .006 & - \\
\hline
\end{tabular}

Note. Latent Class 1 = Extremely low positive traits with high agreeableness, Latent Class $2=$ Low positive traits, Latent Class $3=$ High positive traits with high agreeableness, Latent Class $4=$ High positive traits

Class 3 did not significantly differ from three latent classes in terms of emotion-oriented coping. Individuals with poor positive traits in both Class 1 and Class 2 reported significantly higher scores on parental criticism than individuals with high positive traits allocated in Class 3 and Class 4.

\section{DISCUSSION}

The primary goal of this study was to explore the relations between positive and negative aspects of big five personality traits, multidimensional perfectionism, and generic coping styles, and multidimensional locus of control, irrespective of type of psychological constructs. In such a purpose, scale scores were subjected to a two dimensional EFA in which positive facets of personality, perfectionism, coping and locus of control were successfully distinguished. Secondarily, particular interest was to identify a typology of psychological strengths that positive facets of the observed psychological variables were subjected to a LPA. We obtained four homogenous latent groups best fit to the data: extremely low positive traits with high agreeableness, low positive traits, high positive traits with high agreeableness and high positive traits. The emergent strength typologies classified two of four groups characterized according to the low levels of positive psychological traits and the remained two groups characterized according to the greater levels of positive psychological aspects of respective variables. Individuals with extremely low positive traits with high agreeableness were allocated in Class 1 who reported higher scores on agreeableness in comparison to individuals with low positive traits subsumed in Class 2 . On the other hand, two homogenous groups of positive traits were distinguishable based on agreeableness scores as well. Individuals reported greater scores on agreeableness trait were classified into a distinct group (latent class 3), even though there were no substantial difference in terms of other positive traits between these two high positive traits groups. As expected, most of differences on mean scale scores of negative aspects of psychological variables were not significant across latent classes which can be interpreted in a way that the dependence between positive and negative characteristics of trait psychological variables are not strong as generally conceived. In other words, psychological strengths and vulnerabilities in terms of positive and negative facets of trait variables appeared to operate independently in contrast to the contentions taking these aspects granted simple polarities.

Seligman (2004) argues that positive and negative is not binary opposite referring to the premise that happiness is not simply the absence of unhappiness. For example, getting rid of anger, fear and sadness does not automatically come up with positives such as love, gratitude and joy; actually, being in a state of neutrality which refers to being neither happy or unhappy is 
suggested to be possible and that happiness vs unhappiness are not existential opposites (Pawelski, 2013). The results of this study supported the notion that trait psychological constructs particularly related to personality have positive and negative facets which do not simply operate at polar sides rather operate relatively independently from each other. Moreover, it appeared that positive aspects of psychological traits are closely interrelated and may be functioning reciprocally indeed. There has been a huge literature concerning the strong linkages between addressed variables, particularly crucial connections between positive aspects of these psychological traits. Research has accumulated evidence for significant correlation of positive perfectionism and consciousness replicated across studies, while extraversion, openness, and agreeableness showed an inconsistent pattern of associations with the positive side of perfectionistic strivings (Stoeber \& Otto, 2006; Stoeber, Otto, \& Dalbert, 2009). Internal locus of control and problemfocused coping which have revealed strong within connections have long been recognized as predictor variables in dealing successfully with stressful situations, and thus well-regulated self (Folkman \& Lazarus, 1988; Lefcourt, 1984; Mikulincer, 1994). Our findings wellsupported the aforementioned framework.

To our opinion, psychological strengths exert pivotal influence through positive affect on happiness which is greatly determined by intuitive actions -the other two predictors are biological inclinations and external influences which are relatively less likely to be determined by people (Sheldon, Boehm, \& Lyubomirsky, 2013). The positive affect is spontaneously used in memory to organize thoughts- but that the same was not true for the negative affect (Isen, 2003). The notion that affect is an integral part of thought process and motivation and processing goal has been increasingly recognized and the positive affect seems to be the one most crucial sources of psychological strengths. From this view, positive affect and negative affect do not have the same or parallel effects. More specifically, the ways in which positive affect exert influence on cognition and motivation is not the same with negative affect. Moreover, negative affect always seems to debilitate expected outcomes. Contrarily, negative affect has been found to be much more variable in terms of sometimes increasing expected outcomes or sometimes decreasing it, and sometimes having no effect (Cialdini, Darby, \& Vincent, 1972; Cunningham, Steinberg, \& Grev, 1980; Isen, 1990, 1999, 2002a). A growing body of research has evidenced that positive feelings facilitate the sought-after abilities of more effective thinking, judgment and functioning (Isen, 2002a, 2002b). Mild positive affect may set in motion other psychological strengths and, in turn, may be influenced by psychological strengths, or vice versa. This sketchy reciprocal model of positive affect engendered by psychological strengths may be extended with incorporating complex relations to goal directed behavior and achievement as well as development of character strengths.

Psychological strengths may give rise to flexible selfregulatory efforts by providing ways to change one's perspective on a problem or by using information from others' experiences in planning one's own course of action (Aspinwall, 2001; Aspinwall, Hill, \& Leaf, 2002). Psychological strengths are relational in nature and the ability to form warm and trustworthy relationships which is probably the greatest human strength (Berscheid, 2003). Inconsistent with the empirical hints and theoretical considerations, agreeableness also appeared to have a paradoxical effect on psychological strengths in two clusters of latent groups. Even though we found a variation in scores of positive facets of the psychological variables across classes, agreeableness was shown to have a critical role in accounting for the differentiation of latent homogenous subgroups. Given the two classes comprised of individuals with low levels of positive traits, agreeableness had a compromising effect that individuals with higher agreeableness reported extremely lower scores on other positive traits in comparison to individuals classified in Class 2 and were subsumed in Class 1. Turning to the two other latent classes with high positive traits, individuals with greater agreeableness trait were discerned from other positive traitors and classified in latent class 3 but did not differ in terms of positive traits other than agreeableness. Most notably, among people lacking of positive traits, agreeableness personality trait 
had a centripetal effect on positive traits that it seemingly debilitates psychological strengths in terms of internal locus of focus, task-oriented coping, organization and other personality traits (extraversion, openness and consciousness) that may render individuals more vulnerable. Moreover, agreeableness trait appears to be operating differently in a way in which can be associated with dependent personality (Wiggins \& Pincus, 1989) and directs to a tendency that compromises development of psychological strengths to an extent among risky individuals with low positive traits.

Eventually, we found that positive aspects of trait psychological variables were less likely to reveal strong connections with negative aspects. Although research has evidenced for that built-up positive developments may be amenable to negatives (Calhoun \& Tedeschi, 2012); we found relatively weak associations between positive and negative facets of the trait variables on which we mainly focused. Using ANOVAs we detected only significant differences for chance dimension of locus of control, emotion-oriented coping and parental criticism

\section{References}

Adkins, K. K., \& Parker, W. (1996). Perfectionism and suicidal preoccupation. Journal ofPersonality, 64(2), 529-543.

Akaike, H. (1987). Factor analysis and AIC. Psychometrica, 52, 317332.

Aspinwall, L. G. (2001). Dealing with adversity: Self-regulation, coping, adaptation, and health. In A. Tesser \& N. Schwarz (Eds.), Blackwell handbook of social psychology: Intraindividual processes (pp. 591-614). Malden, MA: Blackwell Publishers.

Aspinwall, L. G., Hill, D. L., \& Leaf, S. L. (2002). Prospects, pitfalls, and plans: A proactive perspective on social comparison activity. In W. Stroebe \& M. Hewstone (Eds.), European review of social psychology (Vol. Vol. 12, pp. 267-298). New York: John Wiley \& Sons.

Aspinwall, L. G., \& Staudinger, U. M. (2003). A psychology of human strengths: Fundamental questions and future directions for a positive psychology. Washingon, DC: American Psychological Association.

Baltes, P. B., \& Staudinger, U. M. (2000). Wisdom: A metaheuristic (pragmatic) to orchestrate mind and virtue towards excellence. American Psychologist, 55(1), 122-136.

Berscheid, E. (2003). The human's greatest strength: Other humans. In L. G. Aspinwall \& U. M. Staudinger (Eds.), A psychology of human strengths: Fundamental questions and future directions for a positive psychology (pp. 37-47). Washingon, DC: American Psychological Association. across latent homogenous subsets. These findings were in consonance with the prior investigations and theoretical considerations (Lazarus \& Folkman, 1984; Lefcourt, 1984; Linehan, 2014), whilst each negative aspect could merely account for $3-5 \%$ of the variance. It appears that additional conceptualizations are needed to provide more robust explanations for individual differences in psychological strengths.

This study has several limitation that the data was recruited from relatively a small sample. Second, our research design was cross-sectional and we could have found different associations between variables in a longitudinal research design. Although, the study has limitations, these results evidenced for the premise that relations between positive and negative traits can be best understood in a taxonomic model rather than a continuum model.

\section{Disclosure statement}

No potential conflict of interest was reported by the authors.
Biswas-Diener, R. (2006). From the Equator to the North Pole: A study of character strengths. Journal of Happiness Studies, 7(3), 293-310.

Boysan, M. (2012). Validity of the Copng Inventory for Stresful Situations -Short Form (CISS-21) in a non-clinical Turkish sample. Düşünen Adam: the Journal of Psychiatry and Sciences, 25(2), 101-107.

Boysan, M., Keskin, S., \& Beşiroğlu, L. (2008). Assessment of hierarchical factor structure, reliabilty, and validity of the Penn State Worry Questionnaire Turkish version. Bulletin of Clinical Psychopharmachology, 18(3), 174-182.

Calhoun, L. G., \& Tedeschi, R. G. (2012). Posttraumatic growth in clinical practice. New York: Routledge.

Cialdini, R. B., Darby, B., \& Vincent, J. (1972). Transgression and altruism: A case for hedonism. Journal of Experimental Social Psychology, 9, 502-516.

Costa, P. T., \& McCrae, R. R. (1980). Influence of extraversion and neuroticism on subjective well-being: happy and unhappy people. Journal of Personality and Social Psychology Bulletin, 38, 668678.

Costa, P. T., McCrae, R. R., \& Zonderman, A. B. (1987). Environmental and dispositional influences on well-being: longitudinal follow-up of an American national sample. British Journal of Psychology, 78, 299-306 
Csikszentmihalyi, M. (2008). Flow: The psychology of optimal experience. New York: Harper Perennial.

Cunningham, M. R., Steinberg, J., \& Grev, R. (1980). Wanting to and having to help: Separate motivations for positive mood and guilt induced helping. Journal of Personality and Social Psychology, 38, 181- 192

Davidson, R. J. (1992). Emotion and affective style: hemispheric substrates. Psychological Science, 3(1), 39-43. doi: DOI 10.1111/ j.1467-9280.1992.tb00254.x

Davidson, R. J., \& Sutton, S. K. (1995). Affective neuroscience: The emergence of a discipline. Current Opinions in Neurobiology, 5(2), 217-224.

Diener, E., Suh, E. M., Lucas, R. E., \& Smith, H. L. (1999). Subjective well-being: Three decades of progress. Psychological Bulletin, 125(2), 276-302. doi: Doi 10.1037/0033-2909.125.2.276

Endler, N. S., \& Parker, J. D. A. (1990). Coping Inventory for Stressful Sitations (CISS): Manual. Toronto: Multi-Health Systems.

Eryilmaz, A. (2012). A model of subjective well-being for adolescents in high school. Journal of Happiness Studies, 13(2), 275-289. doi: DOI 10.1007/s10902-011-9263-9

Evinç, S. G. (2004). Maternal personality characteristics, affective state, and psychopathology in relation to children's attention deficit and hyperactivity disorder and comorbid symptoms. (Unpublished master dissertation), Middle East Technical University, Ankara.

Folkman, S., \& Lazarus, R. S. (1988). Coping as a mediator of emotion. Journal of Personality and Social Psychology, 54(3), 466-475. doi: Doi 10.1037/0022-3514.54.3.466

Frost, R. O., Heimberg, R. G., Holt, C. S., Mattia, J. I., \& Neubauer, A. L. (1993). A comparison of two measures of perfectionism. Personality and Individual Differences, 14(1), 119-126. doi: Doi 10.1016/0191-8869(93)90181-2

Frost, R. O., Marten, P., Lahart, C., \& Rosenblate, R. (1990). The dimensions of perfectionism. Cognitive Therapy and Research, 14(5), 449-468. doi: Doi 10.1007/Bf01172967

Hamachek, D. E. (1978). Psychodynamics of normal and neurotic perfectionism. Psychology: A Journal of Human Behavior, 15(1), 27-33.

Hewitt, P. L., \& Flett, G. L. (2004). Multidimensional Perfectionism Scale (MPS): Technical manual. Toronto, Canada: Multi-Health Systems.

Huta, V., \& Hawley, L. (2010). Psychological Strengths and Cognitive Vulnerabilities: Are They Two Ends of the Same Continuum or Do They Have Independent Relationships with Well-being and Ill-being? Journal of Happiness Studies, 11(1), 71-93. doi: DOI 10.1007/s10902-008-9123-4

Isen, A. M. (1990). The influence of positive and negative affect on cognitive organization: Implications for development. In N. Stein, B. Leventhal \& T. Trabasso (Eds.), Psychological and biological processes in the development of emotion (pp. 75-94). Hillsdale, NJ: Erlbaum.

Isen, A. M. (1999). On the relationship between affect and creative problem solving. In S. Russ (Ed.), Affect, creative experience, and psychological adjustment (pp. 3- 17). Philadelphia: Taylor \& Francis. Isen, A. M. (2002a). Missing in action in the AIM: Positive affect's facilitation of cognitive flexibility, innovation, and problem solving. Psychological Inquiry, 13(1), 57-65.

Isen, A. M. (2002b). A Role for neuropsychology in understanding the facilitating influence of positive affect on social behavior and cognitive processes. In C. R. Snyder \& S. J. Lopez (Eds.), Handbook of positive psychology (pp. 528-541). Oxford: Oxford University Press.
Isen, A. M. (2003). Positive affect as a source of human strength In L. G. Aspinwall \& U. M. Staudinger (Eds.), A psychology of human strengths: Fundamental questions and future directions for a positive psychology (pp. 179-195). Washingon, DC: American Psychological Association.

John, O. P., \& Srivastava, S. (1999). The big five trait taxonomy: History, measurement, and theoretical perspectives. In L. A. Pervin $\&$ O. P. John (Eds.), Handbook of personality: Theory and research (2 $2^{\text {nd }}$ Ed ed., pp. 102-138). New York: Guilford Press.

Judge, T. A., Erez, A., Bono, J. E., \& Thoresen, C. J. (2002). Are measures of self-esteem, neuroticism, locus of control, and generalized self-efficacy indicators of a common core construct? Journal of Personality and Social Psychology, 83(3), 693-710. doi: Doi 10.1037//0022-3514.83.3.693

Judge, T. A., Locke, E. A., \& Durham, C. C. (1997). The dispositional causes of job satisfaction: A core evaluations approach. Research in Organizational Behavior, 1997, 19, 151-188.

Kağan, M. (2011). Psychometric properties of the Turkish version of the Frost Multidimensional Perfectionism Scale. Anatolian Journal of Psychiatry, 12(3), 192-197.

Kıral, E. (2012). The relationship between locus of control and perfectionism perception of the primary school administrators. (Unpublished Doctorate Dissertation), Ankara University, Ankara.

Lazarus, R. S., \& Folkman, S. (1984). Stress, appraisal, and coping. New York: Springer.

LeDoux, J. (1996). The emotional brain. New York: Touchstone Books.

Lefcourt, H. (1984). Research with the locus of control: limitations and extention (Vol. Vol 3). Orlando: Academic Press.

Levenson, H. (1973). Multidimensional locus of control in psychiatric patients. Journal of Consulting and Clinical Psychology, 41, 397-404

Linehan, M. M. (2014). DBT® Skills Training Manual (S. Edition Ed.). New York: Guilford.

McCrae, R. R., \& Costa, P. T. (1991). Adding liebe und arbeit - the full 5-factor model and well-being. Personality and Social Psychology Bulletin, 17(2), 227-232. doi: Doi 10.1177/014616729101700217

McCrae, R. R., \& Costa, P. T. (1996). Toward a new generation of personality theories: theoretical contexts for the five factor model. In J. S. Wiggins (Ed.), The five factor model of personality: theoretical perspectives (pp. 51-87). New York: Guilford Press.

McLachlan, G., \& Peel, D. (2000). Finite mixture models. New York: Wiley.

Meyer, T. .J., Miller, M. L., Metzger, R. L., \& Barkovec, T. J. (1990). Development and validation of the Penn State Worry Questionnaire. Behavior Research and Therapy, 28(6), 487-495.

Mikulincer, M. (1994). Human learned helplessness: a coping perspective. New York: Springer.

Nylund, K. L., Asparoutiov, T., \& Muthen, B. O. (2007). Deciding on the number of classes in latent class analysis and growth mixture modeling: A Monte Carlo simulation study. Structural Equation Modeling-a Multidisciplinary Journal, 14(4), 535-569. doi: Doi 10.1080/10705510701793320

Obsessive Compulsive Cognitions Working Group. (2005). Psychometric validation of the obsessive belief questionnaire and interpretation of intrusions inventory - Part 2: Factor analyses and testing of a brief version. Behaviour Research and Therapy, 43(11), 1527-1542. doi: DOI 10.1016/j.brat.2004.07.010 
Park, N., \& Peterson, C. (2006). Moral competence and character strengths among adolescents: The development and validation of the Values in Action Inventory of Strengths for Youth. Journal of Adolescence, 29(6), 891-909. doi: DOI 10.1016/j. adolescence.2006.04.011

Parkes, K. R. (1984). Locus of control, cognitive appraisal, and coping in stressful episodes. Journal of Personality and Social Psychology, 46(3), 655-668. doi: Doi 10.1037/0022-3514.46.3.655

Pawelski, J. O. (2013). Happiness and its opposites In S. A. David, Boniwell, I., Ayers, A. C. (Ed.), The Oxford handbook of happiness (pp. 326-339). Oxford: Oxford University Press.

Peterson, C., \& Seligman, M. E. P. (2004). Character strengths and virtues: A handbook and classification. New York: Oxford University Press.

Petrosky, M. J., \& Birkimer, J. C. (1991). The relationship among locus of control, coping styles, and psychological symptom reporting. Journal of Clinical Psychology, 47(3), 336-345. doi: Doi 10.1002/1097-4679(199105)47:3<336::AidJclp2270470303>3.0.Co;2-L

Rheaume, J., Freeston, M. H., Ladouceur, R., Bouchard, C., Gallant, L., Talbot, F., \& Vallieres, A. (2000). Functional and dysfunctional perfectionists: are they different on compulsive-like behaviors? Behaviour Research and Therapy, 38(2), 119-128. doi: Doi 10.1016/ S0005-7967(98)00203-4

Rice, K. G., Ashby, J. S., \& Slaney, R. B. (1998). Self-esteem as a mediator between perfectionism and depression: A structural equation analysis. Journal of Counseling Psychology, 45(3), 304314

Ryan, R. M., \& Deci, E. L. (2000). Self-determination theory and the facilitation of intrinsic motivation, social development, and well-being. American Psychologist, 55(1), 68-78. doi: Doi 10.1037//0003-066x.55.1.68

Ryff, C. D. (1989). Happiness Is Everything, or Is It - Explorations on the Meaning of Psychological Well-Being. Journal of Personality and Social Psychology, 57(6), 1069-1081. doi: Doi 10.1037/00223514.57.6.1069

Schwartz, G. (1978). Estimating the dimension of a model. The Annals of Statistics, 6, 461-464.

Sclove, L. (1987). Application of model selection criteria to some problems in multivariate analysis. Psychometrica, 52, 333-343.

Seligman, M. E. P. (2004). Authentic happiness. New York: Atria.

Seligman, M. E. P., \& Csikszentmihalyi, M. (2000). Positive psychology: An introduction. American Psychologist, 55(1), 5-14.

Shafran, R., \& Mansell, W. (2001). Perfectionism and psychopathology: A review of research and treatment. Clinical Psychology Review, 21(6), 879-906. doi: Doi 10.1016/S02727358(00)00072-6

Sheldon, K. M. (2004). Optimal human being: An integrated multilevel perspective. Mahwah: Psychology Press.

Sheldon, K. M., Boehm, J., \& Lyubomirsky, S. (2013). Variety is the spice of happiness: The hedonic adaptation prevention model. In S. A. David, I. Boniwell \& A. C. Ayers (Eds.), The Oxford handbook of happiness (pp. 901-914). Oxford: Oxford University Press.

Shimai, S., Otake, K., Park, N., Peterson, C., \& Seligman, M. E. P. (2006). Convergence of character strengths in American and Japanese young adults. Journal of Happiness Studies, 7(3), 311322.
Staudinger, U. M., Marsiske, M., \& Baltes, P. B. (1995). Resilience and reserve capacity in later adulthood: Potentials and limits of development across the life span. In D. Cicchetti \& D. Cohen (Eds.), Developmental psychopathology: Risk, disorder, and adaptation (Vol. Vol: 2, pp. 801 -847). New York: Wiley.

Staudinger, U. M., \& Pasupathi, M. (2000). Lifespan perspectives on self, personality and social cognition. In T. Salthouse \& F. Craik (Eds.), Handbook of cognition and aging (pp. 633-688). Hillsdale, NJ: Erlbaum

Steel, P., \& Ones, D. S. (2002). Personality and happiness: A nationallevel analysis. Journal of Personality and Social Psychology, 83(3), 767-781. doi: Doi 10.1037//0022-3514.83.3.767

Sternberg, R. J. (1998). A balance theory of wisdom. Review of General Psychology, 2(4), 347-365.

Stoeber, J. (2014). How other-oriented perfectionism differs from self-oriented and socially prescribed perfectionism. Journal of Psychopathology and Behavioral Assessment, 36(2), 329-338. doi: DOI 10.1007/s10862-013-9397-7

Stoeber, J., \& Otto, K. (2006). Positive conceptions of perfectionism: Approaches, evidence, challenges. Personality and Social Psychology Review, 10(4), 295-319. doi: DOI 10.1207/ s15327957pspr1004_2

Stoeber, J., Otto, K., \& Dalbert, C. (2009). Perfectionism and the Big Five: Conscientiousness predicts longitudinal increases in selforiented perfectionism. Personality and Individual Differences, 47(4), 363-368. doi: DOI 10.1016/j.paid.2009.04.004.

Stumpf, H., \& Parker, W. D. (2000). A hierarchical structural analysis of perfectionism and its relation to other personality characteristics. Personality and Individual Differences, 28(5), 837852. doi: Doi 10.1016/S0191-8869(99)00141-5.

Sutton, S. K., \& Davidson, R. J. (1997). Prefrontal brain asymmetry: A biological substrate of the behavioral approach and inhibition systems. Psychological Science, 8(3), 204-210. doi: DOI 10.1111/ j.1467-9280.1997.tb00413.x.

Tabachnich, B. G., \& Fidell, L. S. (2012). Using multivariate statistics (6 $6^{\text {th }}$ Edition ed.). Boston: Pearson.

Terry-Short, L. A., Owens, R. G., Slade, P. D., \& Dewey, M. E. (1995). Positive and negative perfectionism. Personality and Individual Differences, 18, 663-668.

Tkach, C., \& Lyubomirsky, S. (2006). How do people pursue happiness?: Relating personality, happiness-increasing strategies, and well-being. Journal of Happiness Studies, 7(2), 183-225.

Toner, E., Haslam, N., Robinson, J., \& Williams, P. (2012). Character strengths and wellbeing in adolescence: Structure and correlates of the Values in Action Inventory of Strengths for Children. Personality and Individual Differences, 52(5), 637-642. doi: DOI 10.1016/j.paid.2011.12.014.

Ward, C., \& Kennedy, A. (1992). Locus of control, mood disturbance, and social difficulty during cross-cultural transitions. International Journal of Intercultural Relations, 16(2), 175-194. doi: Doi 10.1016/0147-1767(92)90017-O.

Wiggins, J. S., \& Pincus, A. L. (1989). Conceptions of personality disorders and dimensions of personality. Psychological Assessment: A Journal of Consulting and Clinical Psychology, 1(4), $305-316$.

Zuckerman, M. (1995). Good and bad humours: Biochemical bases of personality and its disorders. Psychological Science, 6(6), 325332. 